\title{
Review: depression may increase mortality in coronary heart
} disease

Barth J, Schumacher M, Herrmann-Lingen C. Depression as a risk factor for mortality in patients with coronary heart disease: a meta-analysis. Psychosom Med 2004;66:802-13.

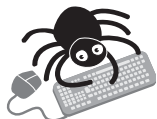

\section{METHODS}

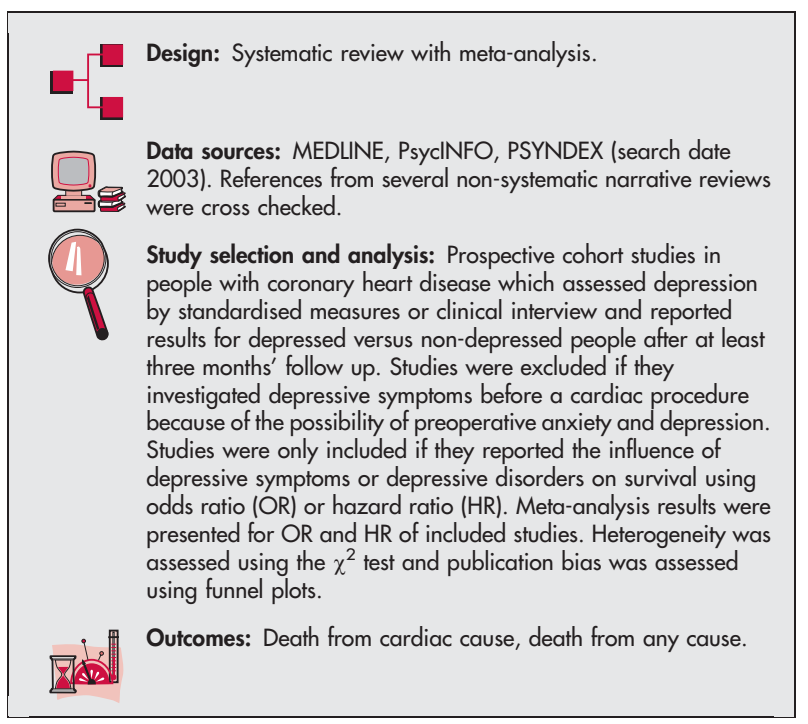

\section{MAIN RESULTS}

Twenty studies met inclusion criteria (11 018 people). Depressive symptoms in people with coronary heart disease increased mortality for all follow up periods, even after adjustment for other risk factors Clinical depression also increased mortality, although this was only significant after six months. After adjustment for other risk factors, clinical depression increased mortality for all follow up periods (see http://www.ebmentalhealth.com/supplemental for table).

\section{CONCLUSIONS}

Depression increases mortality in coronary heart disease. This result should be interpreted with caution because of heterogeneity among the studies included in the meta-analyses.

\section{NOTES}

Some of the meta-analyses showed significant heterogeneity among studies, which reduces the reliability of these results. The funnel plots indicate that there may be publication bias in studies investigating depressive symptoms, which may exaggerate the risk of mortality.

For correspondence: Jürgen Barth, PhD, University of Freiburg, Institute of Psychology, Department of Rehabilitation Psychology, Freiburg, Germany; mail@juergen-barth.de

Sources of funding: none reported

\section{Commentary}

D epressive symptoms are a major concern, as they are frequently associated with morbidity, disability, and mortality. ${ }^{1}$ The prevalence rate of depressive symptoms in community dwelling individuals is high and may be as high as $50 \%$ in populations over 65 years of age. ${ }^{2}$ Behavioural factors, health, and functional status, and psychosocial variables such as loneliness, isolation, and lack of social and family support are considered strong determinants of depressive symptoms. ${ }^{3}$

A recent systematic review has shown that depressive symptoms are associated with the development of coronary heart disease (CHD) in initially healthy people. ${ }^{4}$ The meta-analysis by Barth et al suggests that depressive symptoms are an independent risk factor for mortality in patients with $\mathrm{CHD}$.

Psycho-physiological research has indicated several mechanisms that could explain the association between depressive symptoms and CHD such as: cardiotoxicity of some antidepressant drugs; higher prevalence of cardiac risk factors, including cigarette smoking, hypertension, diabetes, and reduced functional capacity; increased coronary disease severity; non-adherence to cardiac prevention and treatment regimens; lower heart rate variability reflecting altered cardiac autonomic tone; increased platelet aggregation; and inflammatory processes. ${ }^{5}$

The meta-analysis by Barth et al, regardless of the methodological weaknesses acknowledged by the authors, shows that there is no prognostic difference between studies that define depression through selfreport and those using a clinical diagnosis. This is extremely relevant for clinical practice, because it represents a rationale for assessing depressive symptoms routinely in all people with CHD. The diagnostic scales are simple, easy, and quick to administer. The optimal therapeutic approach for people with CHD could include effective treatments for depression. ${ }^{6-8}$

There is epidemiological evidence, and a biological plausibility, for an independent association between depressive symptoms and mortality in people with CHD patients. Valid and reliable instruments for the diagnosis and effective treatments for depressive symptoms are available. It is now time for action.

Stefania Maggi, MD, PhD CNR-Neuroscience Institute, Aging Branch, Padova, Italy

1 Cuijpers P, Schoevers RA. Increased mortality in depressive disorders: a review. Curr Psychiatry Rep 2004;6:430-7.

2 Minicuci N, Maggi S, Pavan M, et al. Prevalence rate and correlates of depressive symptoms in old individuals. The Veneto Study. J Gerontol Biol Sci 2002;57:M55-61.

3 Bromberger JT. A psychosocial understanding of depression in women: for the primary care physician. J Am Med Womens Assoc 2004;59:198-206.

4 Rugulies R. Depression as a predictor for coronary heart disease. Am J Prev Med 2002;23:51-61

5 Carney RM, Freedland KE, Miller GE, et al. Depression as a risk factor for cardiac mortality and morbidity: a review of potential mechanisms. J Psychosom Res 2002:53:897-902.

6 Monster TB, Johnsen SP, Olsen ML, et al. Antidepressants and risk of firsttime hospitalization for myocardial infarction: a population-based casecontrol study. J Med 2004; 117:732-7.

7 Glassman AH, O'Connor CM, Califf RM, et al. The Sertraline Antidepressant Heart Attack Randomized Trial (SADHEART) Group. Sertraline treatment of major depression in patients with acute MI or unstable angina. JAMA 2002;288:701-9.

8 Asarnow JR, Jaycox LH, Duan N, et al. Effectiveness of a quality improvement intervention for adolescent depression in primary care clinics: a randomized controlled trial. JAMA 2005;293:311-19. 